\title{
The Prevalence of Antibiotic Resistance to Polymyxins in Clinical Isolates of Acinetobacter baumannii in Iran and the World: A Systematic Review and Meta-Analysis
}

\author{
Fatemeh Sayehmiri, ${ }^{1}$ Mohammad Yousef Alikhani, ${ }^{2,3,}{ }^{*}$ Kourosh Sayehmiri, ${ }^{4}$ Manoochehr Karami, ${ }^{5}$ and \\ Jalal Ghaderkhani ${ }^{3}$ \\ ${ }^{1}$ Department of Proteomics, Shahid Beheshti University of Medical Sciences, Tehran, IR Iran \\ ${ }^{2}$ Brucellosis Research Center, Hamadan University of Medical Sciences, Hamadan, IR Iran \\ ${ }^{3}$ Department of Epidemiology, Hamadan University of Medical Sciences, Hamadan, IR Iran \\ ${ }^{4}$ Department of Social Medicine, Ilam University of Medical Science, Ilam, IR Iran \\ ${ }^{5}$ Department of Microbiology, Hamadan University of Medical Sciences, Hamadan, IR Iran \\ "Corresponding author: Mohammad Yousef Alikhani, Department of Microbiology and Brucellosis Research Center, School of Medicine, Hamadan University of Medical \\ Sciences, Hamadan, IR Iran. Tel: +98-8138380755, E-mail: alikhani@umsha.ac.ir
}

Received 2017 April 10; Accepted 2017 June 24.

\begin{abstract}
Background: Acinetobacter baumannii is one of the most important opportunistic pathogens responsible for several nosocomial infections. A major problem in treatment is antibiotic resistance.

Methods: By searching international and national databases, including PubMed, Google Scholar, Web of Science, SID, Magiran, IranDoc and IranMedex, 38 articles between years 2002 to 2016 published world-wide were extracted and analyzed using the metaanalysis method and random effects model. The heterogeneity of studies was assessed using the $\mathrm{I}^{2}$ index. Data were analyzed with the R and STATA (Ver 11/2) software.

Results: Forty-three articles were selected for this study. Drug-resistance of Acinetobacter baumannii towards Polymyxin was reported as 5\%, yet for Colistin $4 \%$ was estimated. Resistance rates to Polymyxin and Colistin in the continent of America and Asia was $6 \%$ and Sensitivity rate to Polymyxin and Colistin was $96 \%$ and $80 \%$, respectively.

Conclusions: Given that drug resistance rate of Acinetobacter baumannii to Polymyxin and Colistin in this study was 5\% and 4\%, respectively, thus indicating high sensitivity of Acinetobacter baumannii to these antibiotics, this group can be administered as appropriate therapeutic agents against these bacteria.
\end{abstract}

Keywords: Prevalence of Resistance, Antibiotics, Polymyxins, Colistin, Acinetobacter baumannii

\section{Background}

Acinetobacter baumannii are coccobacillus gramnegative, oxidase negative, strictly aerobic, non-motile, and non-fermentative bacteria that are widely spread in soil and water and also in hospital environments and survives in these environments for a long time and is readily transmitted among patients (1). Due to the significant clinical activity of this bacteria and its ability to acquire antibiotic resistance, it is considered as one of the threatening microorganisms towards antimicrobial drugs (2). The major problem in the treatment of A. baumannii is its ability to acquire resistance to major antibiotic classes (3). Acinetobacter baumannii infections, include nosocomial infections, bacteremia, urinary tract infection, and secondary meningitis, while it has an important role in hospital pneumonia, especially pneumonia in upper respiratory tract hospitalized patients at intensive care units around the world. Acinetobacter baumannii is one of the most common isolates causing sepsis in patients with immune deficiency and is associated with increased risk of mortality (4). It is the most common species from blood, sputum, skin, urine, and pleural fluid isolates (5). Therapeutic problems caused by these bacteria and the possibility of transfer between living and non-living objects and also long-lasting nature in hospital environments has caused enhancement in the appearance of the bacteria in hospital environments and its increasing infection. Therefore, mortality in patients with A. baumannii infections is estimated to be about 75\%. Hospital infections are currently a major problem around the world (6). The major problem in the treatment of infections caused by A. baumannii is the ability of these bacteria to acquire antibiotic resistance towards a large class of antibiotics. The emergence and spread of drug-resistant A. baumannii capable of transferring genetic elements of 
different antibiotic resistance has created a major threat in hospitals (7). One of the therapeutic agents effective against $A$. baumannii is polymyxin group antibiotics, including Polymyxin B and Colistin (Polymyxin E). Colistin is a cationic polypeptide composed of a circular decapeptide. These antibiotics show antimicrobial activity by two mechanisms, including initial connection and permeability of the outer membrane followed by re-establishment of the cytoplasmic membrane. Colistin has the wide antimicrobial spectrum of many gram-negative bacteria and is often considered as one of the last effective antibiotics against multi-resistant A. baumannii isolates. However, in the recent years, clinical isolates resistant to Colistin have also been reported $(8,9)$. Therefore, with regards to the importance of antibiotic resistance rate in clinical isolates of A. baumannii, the information on its statistics worldwide could help health planners in order to prevent the spread of antibiotic resistance and adopt appropriate strategies.

\section{Methods}

This systematic review and meta-analysis study was conducted to assess the prevalence rate of resistance to Polymyxins in clinical isolates of A. baumannii during years 2002 to 2016 in Iran and around the World. To collect the required data from published papers in national and international journals research in different databases was performed, including PubMed, Google Scholar, Scopus, SID, Magiran, and IranMedex. Keywords to search articles included prevalence of resistance, polymyxins, and Acinetobacter baumannii with all combinations possible. After reading the abstract of the articles, related articles were separated.

\subsection{Study Selection Criteria and Data Extraction}

The major inclusion criteria was that the study had to address "prevalence of resistance to the Polymyxin and Colistin in clinical isolates of Acinetobacterbaumannii" and the exclusion criteria of the study was lack of referrence to the prevalence of resistance to antibiotics in clinical isolates of A. baumannii, unrelated studies, and low-quality articles. To begin with, a researcher collected all the articles related to antibiotic resistance and after finishing the search, a list of article abstracts was prepared. At this stage, 156 articles, which mentioned "prevalence of resistance to antibiotics" and "Acinetobacter baumannii and 'polymyxin and colistin' in their titles were entered in the initial list. Then, 46 articles were excluded because of repetition, 34 articles due to differences in the type of criteria used, 23 articles due to low quality, and 11 articles due to the unavailability of the full text. Finally, 43 appropriate articles in order to enter the stage of meta-analysis were selected (Figure 1). Then, for the final evaluation, a checklist of data was prepared. Accordingly, the selected 43 articles were studied. The following information was needed for the study, investigator's name, age, location, the number of samples, and the prevalence of resistance. The underlying data for this study were to interpret the chart insert.

\subsection{Statistical Analysis}

At first in this section, all the prevalence rates of antibiotic resistance were recorded, then to calculate the variance of each study, the binomial distribution formula was used. To combine the prevalence rate of different studies, average weight was used. Each study was weighted inversely proportional to its variance. Due to the large differences in the prevalence rates in various studies (heterogeneity of studies), significant heterogeneity index $\left(\mathrm{I}^{2}\right)$ of the random-effects model was used.

\section{Results}

In the present study to conduct a meta-analysis and systematic review, 43 reports were selected and related articles conducted between 2002 and 2016 were studied. Extracted data are shown in Table 1 . Total specimen volume of the 43 articles was 5360 samples. Drug-resistance of $A$. baumannii towards polymyxins was reported as $5 \%$, according to estimates of 11 papers (Tables 2 - 4 and Figures 2 and 3).

\section{Discussion and Conclusions}

According to results of this study, the prevalence of $A$. baumannii isolates resistant to polymyxins is increasing. According to previous studies, the spread of antibioticresistant A. baumannii isolates and associated therapeutic problems have been approved in Iran and the World. In this study, the resistance rate towards colistin was $4 \%$ and for polymyxin, this was $5 \%$. In the study of Ardabili et al. the pattern of resistance in A. baumannii isolates from patients in Motahari Tehran Hospital Burn Unit was towards 17 antibiotics determined by disk diffusion agar (DDA), while the drug resistance rate towards Colistin was zero percent (39). Moreover, in other studies, this resistance has been reported as zero percent $(13,18,26,41,43)$. In the studies of Shahcheraghi et al. studies (38), Yau et al. (32), Elebd et al. (16) and Al-Agamy et al. (17), this amount was less than 5\%. While in other studies, resistance has been unusually high, such as Youssefian et al. (29) 53.1\%, Vila-Farres et al. (33) 25.6\%, Talebi-Taher et al. (44) (40\%), Ahmadi et al. (37) 39.5\%. 


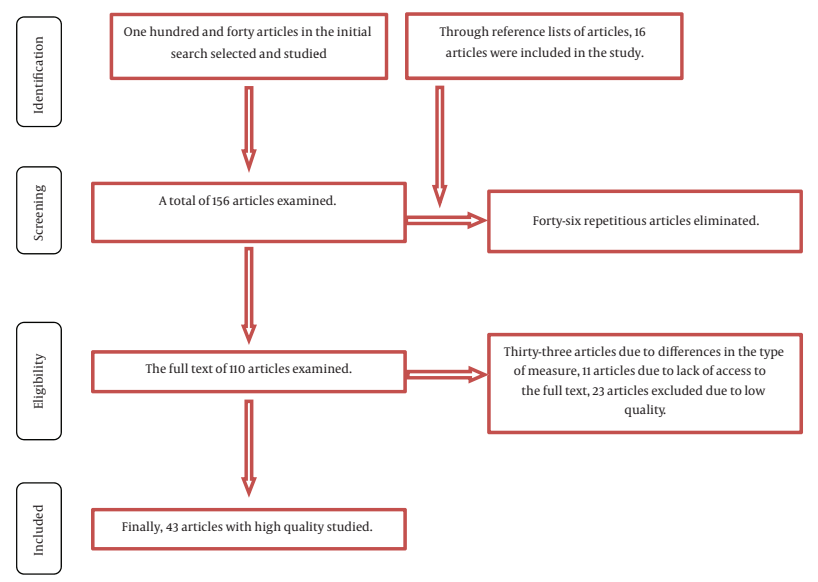

Figure 1. The Stages Entered Into the Systematic Review and Meta-Analysis

Figure 2. The Prevalence of Antibiotic resistance in Acinetobacter baumannii Clinical Isolates to Polymyxin Based on a Random-Effects Model

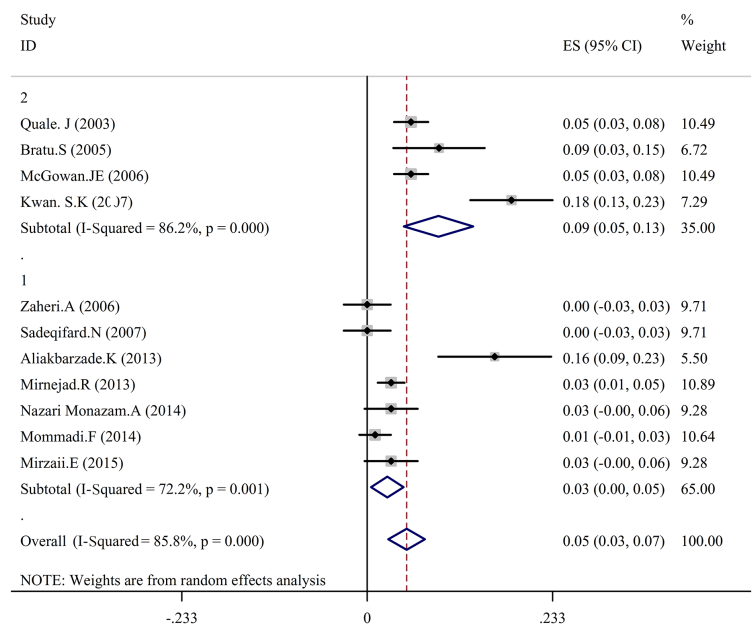

The midpoint of each segment is the estimation of prevalence rate and line length is a confidence interval of $15 \%$ per study and diamond mark shows prevalence rate for all studies (code 1: Iran, code 2: Other countries).

There has been large differences in the resistance rate of the organism towards Colistin. The study of Goudarzi et al. was done by the DDA method, and showed antibiotic resistance rate of A. baumannii in 243 samples to 19 antibiotics; all the samples were susceptible to colistin and tigecycline, so these two antibiotics were suggested for the treatment of A. baumannii (49).

In another study, 108 isolates of A. baumannii were isolated from 2 hospitals in Tehran. Resistance isolates to colistin were determined by DDA; $1.8 \%$ of the isolates were resistant to colistin (50). Polymyxin resistance to A. baumannii obtained in this study are almost consistent with the re- sistance obtained in other studies, including Moammadi et al. 1\% (40), Ardebili et al. 3\% (39), McGowan and Carlet 5.5\% (36), Bratu et al. 9\% (30), Nazari Monazam et al. 3\% (27), Mirzaii 3\% (20), and Quale et al. 5.5\% (11). While in other studies, such as Aliakbarzadeh et al. (16\%) (42) and Ko et al. (18\%) (12) higher resistance rates were reported. Dispute in the findings with the results of this study could be attributed to differences in methods (51-54). The DDA method is a common method for determining susceptibility to antibiotics used, yet evaluation of susceptibility to antibiotics has shown DDA diverse methods compared to methods based on minimum inhibitory concentration 
Table 1. General Information and Data Entered in the Meta-Analysis Studies

\begin{tabular}{|c|c|c|c|c|c|c|c|c|}
\hline \multirow[t]{3}{*}{ First Author } & \multirow[t]{3}{*}{ Study Location } & \multirow[t]{3}{*}{ Publication Year } & \multirow[t]{3}{*}{ The number of Samples } & \multirow[t]{3}{*}{ Study Type } & \multicolumn{4}{|c|}{ The Sensitivity and Resistance Rate of Acinetobacter baumannii to Polymyxins, \% } \\
\hline & & & & & \multicolumn{2}{|c|}{ Polymyxin } & \multicolumn{2}{|c|}{ Colistin } \\
\hline & & & & & Sensitivity,\% & Resistance,\% & Sensitivity,\% & Resistance,\% \\
\hline Quale (11) & New York & 2003 & 433 & Case study & 94.5 & 5.5 & & \\
\hline Kwan (12) & Korea & 2007 & 214 & Cohort & 18 & & 30.6 & \\
\hline Lolans (13) & India & 2006 & 94 & Case study & & & 100 & 0 \\
\hline Gur (14) & Turkey & 2008 & 321 & Cohort & 99.3 & 0.7 & & \\
\hline Bpharm (15) & Syria & 2012 & 260 & Cohort & & & 93.1 & \\
\hline Elabd (16) & Saudi Arabia & 2014 & 108 & Case study & & & 4.6 & 0 \\
\hline Mohamed (17) & Egypt & 2014 & 40 & Case study & & & 95 & 5 \\
\hline Carretto (18) & Italy & 2011 & 277 & Case study & & & 100 & 0 \\
\hline Livermore (19) & London & 2010 & 166 & Cohort & & & 99.4 & \\
\hline Anguti (21) & Iran & 2015 & 61 & Cross sectional & & & 89 & \\
\hline Scheetz (22) & USA & 2007 & 93 & Cohort & 100 & & & \\
\hline Song (23) & Korea & 2007 & 43 & Cohort & & & 100 & 0 \\
\hline $\operatorname{Lim}(24)$ & Singapore & 2010 & 31 & Case study & 100 & 0 & & \\
\hline Alaii (25) & Iran & 2014 & 85 & Cross sectional & & & 71 & 16 \\
\hline Sadeqifard (26) & Iran & 2007 & 66 & Case study & 84.8 & & 100 & 0 \\
\hline Nazari Monazam (27) & Iran & 2014 & 100 & Cross sectional & 97 & 3 & & \\
\hline Noormohamad (28) & Iran & 2014 & 100 & Cross-sectional & & & 7 & 24 \\
\hline Yosefiyan (29) & Iran & 2015 & 96 & Case study & & & & 53.1 \\
\hline Bratu (30) & USA & 2005 & 96 & Cohort & 91 & 9 & & \\
\hline Dizbay (31) & Turkey & 2008 & 66 & Cross sectional & & & 100 & 0 \\
\hline Yau (32) & Africa & 2009 & 30 & Cohort & & & 96.7 & 3.3 \\
\hline Vila-Farres (33) & & 2011 & 14 & Case study & & & 0.5 & 25.6 \\
\hline McGowan (36) & USA & 2006 & 433 & Case study & 94.5 & 5.5 & & \\
\hline Ahmadi (37) & Iran & 2014 & 43 & Case study & & & 60.5 & 39.5 \\
\hline Shahcheraghi (38) & Iran & 2009 & 95 & cross-sectional & & & & 4.2 \\
\hline Ardebili (39) & Iran & 2012 & 65 & Case study & & & & 0 \\
\hline Mohammadi (40) & Iran & 2014 & 97 & Case study & 98.9 & 1 & & \\
\hline $\operatorname{Dinh}$ Van $(41)$ & USA & 2014 & 63 & Case study & & & 100 & 0 \\
\hline Aliakbarzade (42) & Iran & 2013 & 103 & Case study & 84 & 16 & 77 & 19 \\
\hline Hernandes-Torres (43) & Spain & 2012 & 77 & Case study & & & 100 & 0 \\
\hline Sadeghifard (26) & Iran & 2006 & 66 & Case study & 84.8 & 0 & 100 & 0 \\
\hline Talebi-Taher (44) & Iran & 2012 & 35 & Cross sectional & & & 21 & 40 \\
\hline Nasrolahei (45) & Iran & 2014 & 100 & & & & 88.7 & \\
\hline Bayram (46) & Turkey & 2013 & 377 & & & & 100 & 0 \\
\hline Morkel (47) & Africa & 2014 & 17 & Retrospective & & & 71 & 29 \\
\hline Kumar (48) & India & 2014 & 65 & Retrospective & & & 100 & 0 \\
\hline
\end{tabular}

(MIC), which have a higher error rate. On the other hand, the geographical differences in the area of sample isolation are also effective in the pattern of antibiotic resistant isolates; depending on the type of treatment strategy used, the resistance pattern changes. However, it should be noted that the results of epidemiological studies on antibiotic resistance of bacteria are not always predictable. Since
Polymyxin is used as the last line of these bacteria, increasing resistance to these antibiotics is a dangerous alarm for health systems. Thus, the application of new therapeutic regimens, more sensitive diagnostic methods, and control of hospital infections seems essential. 
Table 2. The Resistance of Acinetobacter baumannii Against Polymyxins in Terms of the Number Entered in the Study Meta-Analysis

\begin{tabular}{|c|c|c|c|c|c|c|}
\hline Antibiotic & & Study Number & Prevalence & $\begin{array}{l}\text { Confidence Interval 95\% } \\
\text { (CI\%95) }\end{array}$ & Heterogeneity IndexI ${ }^{2}$,\% & P Value \\
\hline \multirow{2}{*}{ Polymyxin } & Resistance & 11 & 5 & $0.03-0.07$ & 85.8 & 0.000 \\
\hline & Sensitivity & 13 & 96 & $0.95-0.98$ & 86.9 & 0.000 \\
\hline \multirow{2}{*}{ Colistin } & Resistance & 21 & 4 & $0.03-0.5$ & 93.8 & 0.000 \\
\hline & Sensitivity & 22 & 80 & $0.77-0.83$ & 99.9 & 0.000 \\
\hline
\end{tabular}

Table 3. Acinetobacter Baumannii Resistance to Polymyxins in Terms of Study Site Entered in the Meta-Analysis

\begin{tabular}{|c|c|c|c|c|c|c|}
\hline Antibiotic & Continent & & Prevalence & $\begin{array}{c}\text { Confidence Interval 95\% } \\
\text { (CI\%95) }\end{array}$ & Heterogeneity IndexI ${ }^{2}$,\% & P Value \\
\hline \multirow{6}{*}{ Polymyxin } & \multirow{2}{*}{ America } & Resistance & 6 & $0.03-0.09$ & 20.6 & 0.262 \\
\hline & & Sensitivity & 96 & $0.91-1.00$ & 89.1 & 0.000 \\
\hline & \multirow{2}{*}{ Asia } & Resistance & 5 & $0.02-0.08$ & 87.8 & 0.000 \\
\hline & & Sensitivity & 97 & $0.95-0.99$ & 84.4 & 0.000 \\
\hline & \multirow{2}{*}{ Europe } & Resistance & 5 & $0.03-0.08$ & 0.0 & 0.000 \\
\hline & & Sensitivity & 94 & $0.92-0.97$ & 0.0 & 0.000 \\
\hline \multirow{6}{*}{ Colistin } & \multirow{2}{*}{ Africa } & Resistance & 3 & $0.03-0.10$ & 0.0 & - \\
\hline & & Sensitivity & 86 & $0.61-1.11$ & 80.1 & 0.025 \\
\hline & \multirow{2}{*}{ Asia } & Resistance & 6 & $0.04-07$ & 94.9 & 0.000 \\
\hline & & Sensitivity & 73 & $069-0.77$ & 95.1 & 0.000 \\
\hline & \multirow{2}{*}{ Europe } & Resistance & 1 & $-0.01-0.02$ & 68.2 & 0.024 \\
\hline & & Sensitivity & 100 & $0.99-1.00$ & 0.0 & 0.422 \\
\hline
\end{tabular}

Table 4. Acinetobacter baumannii Resistance to Polymyxins in Iran and Other Countries

\begin{tabular}{|c|c|c|c|c|c|c|}
\hline Antibiotic & Location & & Prevalence & $\begin{array}{c}\text { Confidence Interval 95\% } \\
\text { (CI\%95) }\end{array}$ & $\begin{array}{c}\text { Heterogeneity IndexI }^{2} \\
(\%)\end{array}$ & P Value \\
\hline \multirow{4}{*}{ Polymyxin } & \multirow{2}{*}{ Iran } & Resistance & 3 & $0.00-0.05$ & 72.2 & 0.001 \\
\hline & & Sensitivity & 95 & $0.92-0.98$ & 88.2 & 0.00 \\
\hline & \multirow{2}{*}{ Other countries } & Resistance & 9 & $0.05-0.13$ & 86.2 & 0.000 \\
\hline & & Sensitivity & 97 & $0.97-0.99$ & 86.9 & 0.000 \\
\hline \multirow{4}{*}{ Colistin } & \multirow{2}{*}{ Iran } & Resistance & 14 & $0.07-0.21$ & 95.0 & 0.000 \\
\hline & & Sensitivity & 72 & $0.56-0.88$ & 99.4 & 0.000 \\
\hline & \multirow{2}{*}{ Other countries } & Resistance & 1 & $0.00-0.02$ & 91.0 & 0.000 \\
\hline & & Sensitivity & 83 & $0.80-0.87$ & 99.7 & 0.000 \\
\hline
\end{tabular}

\section{References}

1. Peleg AY, Seifert H, Paterson DL. Acinetobacter baumannii: emergence of a successful pathogen. Clin Microbiol Rev. 2008;21(3):538-82. doi: 10.1128/CMR.00058-07. [PubMed: 18625687].

2. Fournier PE, Richet $H$. The epidemiology and control of Acinetobacter baumannii in health care facilities. Clin Infect Dis. 2006;42(5):692-9. doi: 10.1086/500202. [PubMed: 16447117].

3. Patwardhan RB, Dhakephalkar PK, Niphadkar KB, Chopade BA. Astudy on nosocomial pathogens in ICU with special reference to multiresis- tant Acinetobacter baumannii harbouring multiple plasmids. Indian JMed Res. 2008;128(2):178-87. [PubMed: 19001682].

4. Jasemi SS, Alipour F, Dehbashi S, Mardaneh J. Isolation pseudomonas and acinetobacter from blood specimens in patients hospitalized in emam khomeini Hospital (Kermanshah). ISMJ. 2015;18(2):323-33.

5. Hanlon G. The emergence of multidrug resistant Acinetobacter species: a major concern in the hospital setting. Lett Appl Microbiol. 2005;41(5):375-8 
Figure 3. The Prevalence of Antibiotic Resistance in Acinetobacter baumannii Clinical Isolates to Colistin Based on a Random-Effects Model

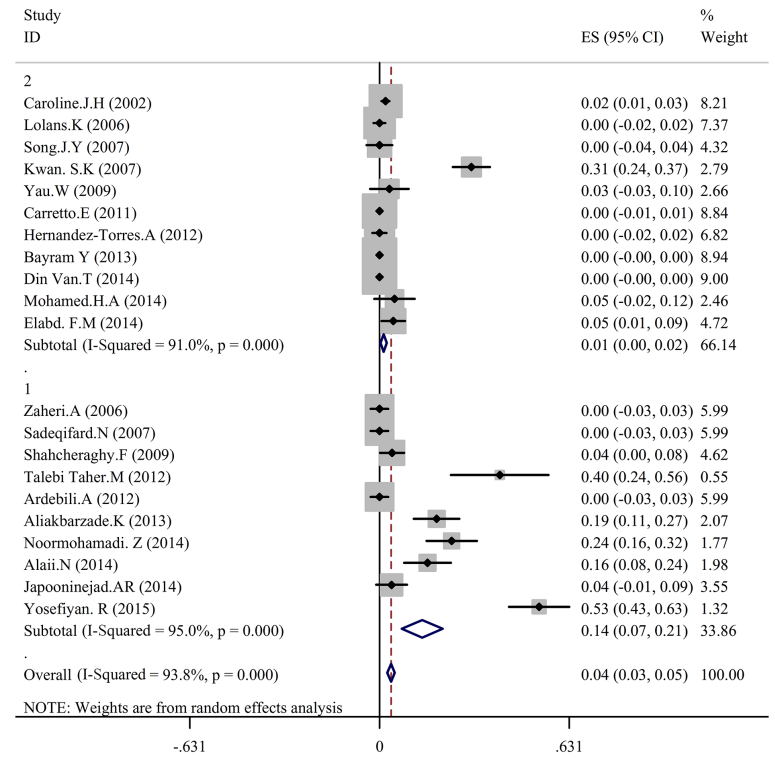

The midpoint of each segment is the estimation of prevalence rate and line length is a confidence interval of $15 \%$ per study and the diamond mark shows the prevalence rate for all studies (code 1: Iran, code 2: Other countries).

6. Fagon JY, Chastre J, Domart Y, Trouillet JL, Gibert C. Mortality due to ventilator-associated pneumonia or colonization with Pseudomonas or Acinetobacter species: assessment by quantitative culture of samples obtained by a protected specimen brush. Clin Infect Dis. 1996;23(3):538-42. [PubMed: 8879777].

7. Navon-Venezia S, Ben-Ami R, Carmeli Y. Update on Pseudomonas aeruginosa and Acinetobacter baumannii infections in the healthcare setting. Curr Opin Infect Dis. 2005;18(4):306-13. [PubMed: 15985826].

8. Feizabadi MM, Fathollahzadeh B, Taherikalani M, Rasoolinejad M, Sadeghifard N, Aligholi M, et al. Antimicrobial susceptibility patterns and distribution of blaOXA genes among Acinetobacter spp. Isolated from patients at Tehran hospitals. Jpn J Infect Dis. 2008;61(4):274-8. [PubMed: 18653968].

9. Moffatt JH, Harper M, Harrison P, Hale JD, Vinogradov E, Seemann $\mathrm{T}$, et al. Colistin resistance in Acinetobacter baumannii is mediated by complete loss of lipopolysaccharide production. Antimicrob Agents Chemother. 2010;54(12):4971-7. doi: 10.1128/AAC.00834-10. [PubMed: 20855724].

10. Kooti S, Motamedifar M, Sarvari J. Antibiotic Resistance Profile and Distribution of Oxacillinase Genes Among Clinical Isolates of Acinetobacter baumannii in Shiraz Teaching Hospitals, 2012 - 2013. Jundishapur J Microbiol. 2015;8(8):e20215. doi: 10.5812/jjm.20215v2. [PubMed: 26464764].

11. Quale J, Bratu S, Landman D, Heddurshetti R. Molecular epidemiology and mechanisms of carbapenem resistance in Acinetobacter baumannii endemic in New York City. Clin Infect Dis. 2003;37(2):214-20. doi: 10.1086/375821. [PubMed: 12856214].

12. Ko KS, Suh JY, Kwon KT, Jung SI, Park KH, Kang CI, et al. High rates of resistance to colistin and polymyxin B in subgroups of Acinetobacter baumannii isolates from Korea. J Antimicrob Chemother. 2007;60(5):1163-7. doi:10.1093/jac/dkm305. [PubMed: 17761499].

13. Lolans K, Rice TW, Munoz-Price LS, Quinn JP. Multicity outbreak of carbapenem-resistant Acinetobacter baumannii isolates pro- ducing the carbapenemase OXA-40. Antimicrob Agents Chemother. 2006;50(9):2941-5. doi: 10.1128/AAC.00116-06. [PubMed: 16940085].

14. Gur D, Korten V, Unal S, Deshpande LM, Castanheira M. Increasing carbapenem resistance due to the clonal dissemination of oxacillinase (OXA-23 and OXA-58)-producing Acinetobacter baumannii: report from the Turkish SENTRY Program sites. J Med Microbiol. 2008;57(Pt 12):1529-32. doi: 10.1099/jmm.0.2008/002469-0. [PubMed: 19018025].

15. Hamzeh AR, Al Najjar M, Mahfoud M. Prevalence of antibiotic resistance among Acinetobacter baumannii isolates from Aleppo, Syria. Am J Infect Control. 2012;40(8):776-7. doi: 10.1016/j.ajic.2011.09.019. [PubMed: 22305413].

16. Elabd FM, Al-Ayed MS, Asaad AM, Alsareii SA, Qureshi MA Musa HA. Molecular characterization of oxacillinases among carbapenem-resistant Acinetobacter baumannii nosocomial isolates in a Saudi hospital. J Infect Public Health. 2015;8(3):242-7. doi: 10.1016/j.jiph.2014.10.002. [PubMed: 25466594].

17. Al-Agamy MH, Khalaf NG, Tawfick MM, Shibl AM, El Kholy A Molecular characterization of carbapenem-insensitive Acinetobacter baumannii in Egypt. Int J Infect Dis. 2014;22:49-54. doi: 10.1016/j.ijid.2013.12.004. [PubMed: 24607428].

18. Carretto E, Barbarini D, Dijkshoorn L, van der Reijden TJ, Brisse S, Passet V, et al. Widespread carbapenem resistant Acinetobacter baumannii clones in Italian hospitals revealed by a multicenter study. Infect Genet Evol. 2011;11(6):1319-26. doi: 10.1016/j.meegid.2011.04.024. [PubMed: 21554997].

19. Livermore DM, Hill RL, Thomson H, Charlett A, Turton JF, Pike R, et al. Antimicrobial treatment and clinical outcome for infections with carbapenem- and multiply-resistant Acinetobacter baumannii around London. Int J Antimicrob Agents. 2010;35(1):19-24. doi: 10.1016/j.ijantimicag.2009.09.014. [PubMed: 19910162].

20. Mirzaii E, Hosayni Dost R, Mirnejad R, Haqiqat SHR. Molecular typing of Clinical isolates ofA. baumanniiin Tehran with the methodpulsedfield gel electrophoresis. Med Sci. 1993;67:61-9.

21. Anguti G, Ghodarzi H, Besharat M, Hajizadeh M. Acinetobacter bau- 
mannii strains in isolated from patients admitted to study drug resistance In Imam Reza Haspital of ( AS) Tabriz,2013. J Med Shahid Beheshti Univ Med Sci. 2014;28(2):106-10.

22. Scheetz MH, Qi C, Warren JR, Postelnick MJ, Zembower T, Obias A, et al. In vitro activities of various antimicrobials alone and in combination with tigecycline against carbapenem-intermediate or -resistant Acinetobacter baumannii. Antimicrob Agents Chemother. 2007;51(5):1621-6. doi: 10.1128/AAC.01099-06. [PubMed: 17307973].

23. Song JY, Kee SY, Hwang IS, Seo YB, Jeong HW, Kim WJ, et al. In vitro activities of carbapenem/sulbactam combination, colistin, colistin/rifampicin combination and tigecycline against carbapenem-resistant Acinetobacter baumannii. J Antimicrob Chemother. 2007;60(2):317-22. doi: 10.1093/jac/dkm136. [PubMed 17540672].

24. Lim TP, Tan TY, Lee W, Sasikala S, Tan TT, Hsu LY, et al. In-vitro activity of polymyxin B, rifampicin, tigecycline alone and in combination against carbapenem-resistant Acinetobacter baumannii in Singapore. PLoS One. 2011;6(4):e18485. doi: 10.1371/journal.pone.0018485 [PubMed: 21533030].

25. Alaee N, Bahador A, Harzandi N. Molecular epidemiology \& antimicrobial resistance of acinetobacter baumannii isolated from namazi hospital, in shiraz by modified aflp analysis. J Microb World. 2013;6(2):91-104

26. Sadegifard N, Ranjbar R, Ghasemi A, Pakzad I, Zaemi Yazdi J, Zaheri A. Evaluation of drug resistance of Acinetobacter baummanni and other Acinetobacter species isolated from three hospitals in Tehran.J Ilam Univ Med Sci. 2006;14(3):29-36.

27. Nazari Monazam A, Hosseini Doust SR, Mirnejad R. Prevalence PER and VEB beta-lactamase Genes among Acinetobacter baumannii Isolated from Patients in Tehran by PCR. Iran J Med Microbiol. 2015;8(4):28-35.

28. Normohamady Z, Zamanzad B, Shavarzi A, Kiani P. Evaluation antimicrobial resistance of Acinetobacter baumannii isolated from Shahrekord teaching hospitals in 2013. J Shahrekord Univ Med Sci. 2015;16(6):1-8.

29. Yousefian R, Karbasizadeh V, Sh M. Identification and Frequency of Colistin-Resistant Acintobacter Baumanii in Clinical Isolates using Polymerase Chain Reaction. J Isfahan Med School. 2014;32(301):146674.

30. Bratu S, Landman D, Martin DA, Georgescu C, Quale J. Correlation of antimicrobial resistance with beta-lactamases, the OmpAlike porin, and efflux pumps in clinical isolates of Acinetobacter baumannii endemic to New York City. Antimicrob Agents Chemother. 2008;52(9):2999-3005. doi: 10.1128/AAC.01684-07. [PubMed: 18591275].

31. Dizbay M, Altuncekic A, Sezer BE, Ozdemir K, Arman D. Colistin and tigecycline susceptibility among multidrug-resistant Acinetobacter baumannii isolated from ventilator-associated pneumonia. Int J Antimicrob Agents. 2008;32(1):29-32. doi: 10.1016/j.ijantimicag.2008.02.016. [PubMed: 18539006].

32. Yau W, Owen RJ, Poudyal A, Bell JM, Turnidge JD, Yu HH, et al. Colistin hetero-resistance in multidrug-resistant Acinetobacter baumannii clinical isolates from the Western Pacific region in the SENTRY antimicrobial surveillance programme. J Infect. 2009;58(2):138-44. doi: 10.1016/j.jinf.2008.11.002. [PubMed:19058855]

33. Vila-Farres X, Garcia de la Maria C, Lopez-Rojas R, Pachon J, Giralt E, Vila $J$. In vitro activity of several antimicrobial peptides against colistinsusceptible and colistin-resistant Acinetobacter baumannii. Clin Microbiol Infect. 2012;18(4):383-7. doi: 10.1111/j.1469-0691.2011.03581.x. [PubMed: 21672084].

34. Japoni-Nejad A, Sofian M, Belkum A, Ghaznavi-Rad E. Nosocomial Outbreak of Extensively and Pan Drug-Resistant Acinetobacter baumannii in Tertiary Hospital in Central Part of Iran. Jundishapur J Microbiol. 2013;6(8) doi: 10.5812/jjm.9892.

35. Mirnejad R, Vafaei S. Antibiotic resistance patterns and the prevalence of ESBLs among strains of Acinetobacter baumannii isolated from clinical specimens. J Genes Microbes Immun. 2013;2013:1-8. doi: 10.5899/2013/jgmi-00002.

36. McGowan JJ, Carlet J. Antimicrobial resistance: a worldwide problem for health care institutions. Am J Infect Control. 1998;26(6):541-3. doi: 10.1053/ic.1998.v26.a95051. [PubMed: 9836835].

37. Ahmadi K, Mardaneh J, Saadat S. Determination antimicrobial resistance profile of Acinetobacter strains isolated from hospitalized patients in Different Part of Taleghani Hospital (Ahvaz, Iran). ISMJ. 2014;17(4):620-8.

38. Shahcheraghi F, Abbasalipour M, Feizabadi M, Ebrahimipour G, Akbari N. Isolation and genetic characterization of metallo-betalactamase and carbapenamase producing strains of Acinetobacter baumannii from patients at Tehran hospitals. Iran J Microbiol. 2011;3(2):68-74. [PubMed: 22347585].

39. Ardebili A, Azimi L, Mohammadi-Barzelighi H, Beheshti M, Talebi M, Jabbari M, et al. Determination of resistance pattern of isolated acinetobacter baumannii from hospitalized burned patients in Motahari Hospital, Tehran. ZUMS J. 2012;20(83):112-9.

40. Moammadi F, Arabestani MR, Safari M, Roshanaii G, Alikhani MY. Prevalence of class1, 2 and 3 integrons among extensive drug resistance Acinetobacter baumanii strains isolated from intensive care units in Hamadan, west province, Iran. Iran J Med Microbiol. 2014;8(3):8-14.

41. Van TD, Dinh QD, Vu PD, Nguyen TV, Pham CV, Dao TT, et al. Antibiotic susceptibility and molecular epidemiology of Acinetobacter calcoaceticus-baumannii complex strains isolated from a referral hospital in northern Vietnam. J Glob Antimicrob Resist. 2014;2(4):31821. doi: 10.1016/j.jgar.2014.05.003. [PubMed: 25540720].

42. Aliakbarzade K, Farajnia S, Karimi Nik A, Zarei F, Tanomand A. Prevalence of Aminoglycoside Resistance Genes in Acinetobacter baumannii Isolates. Jundishapur J Microbiol. 2014;7(8) doi: 10.5812/jjm.11924.

43. Hernandez-Torres A, Garcia-Vazquez E, Gomez J, Canteras M, Ruiz J, Yague G. Multidrug and carbapenem-resistant Acinetobacter baumannii infections: Factors associated with mortality. Med Clin (Barc). 2012;138(15):650-5. doi:10.1016/j.medcli.2011.06.024. [PubMed: 22093403].

44. Talebi-Taher M, Latifnia M, Javad-Moosavai SA, Adabi M, Sh B. Risk factors and antimicrobial susceptibility in ventilator associated pneumonia: a brief report. Tehran Univ Med Sci. 2012;70(9).

45. Nasrolahei M, Zahedi B, Bahador A, Saghi H, Kholdi S, Jalalvand N, et al. Distribution of bla(OXA-23), ISAba , Aminoglycosides resistant genes among burned \& ICU patients in Tehran and Sari, Iran. Ann Clin Microbiol Antimicrob. 2014;13:38. doi: 10.1186/s12941-014-0038-0. [PubMed: 25252850].

46. Bayram Y, Gultepe B, Bektas A, Parlak M, Guducuoglu H. Evaluation of Antibiotic Resistance in Acinetobacter baumannii Strains Isolated from Various Clinical Samples. Klimik Dergisi/Klimik J. 2015;26(2):4953. doi: 10.5152/kd.2013.17.

47. Morkel G, Bekker A, Marais BJ, Kirsten G, van Wyk J, Dramowski A. Bloodstream infections and antimicrobial resistance patterns in a South African neonatal intensive care unit. Paediatr Int Child Health. 2014;34(2):108-14. doi: 10.1179/2046905513Y.0000000082. [PubMed: 24621234].

48. Kumar A, Randhawa VS, Nirupam N, Rai Y, Saili A. Risk factors for carbapenem-resistant Acinetobacter baumanii blood stream infections in a neonatal intensive care unit, Delhi, India. J Infect Dev Ctries. 2014;8(8):1049-54. doi: 10.3855/jidc.4248. [PubMed: 25116673].

49. Goudarzi H, Douraghi M, Ghalavand Z, Goudarzi M. Assessment of antibiotic resistance pattern in Acinetobacter bumannii carrying bla oxA type genes isolated from hospitalized patients. Novel Biomed. 2013;1(2):54-61.

50. Noori M, Karimi A, Fallah F, Hashemi A, Alimehr S, Goudarzi H, et al. High Prevalence of Metallo-beta-lactamase Producing Acinetobacter baumannii Isolated From Two Hospitals of Tehran, Iran. Arch Pediatr Infect Dis. 2014;2(1) doi: 10.5812/pedinfect.15439.

51. Gales AC, Reis AO, Jones RN. Contemporary assessment of antimicro- 
bial susceptibility testing methods for polymyxin B and colistin: review of available interpretative criteria and quality control guidelines. J Clin Microbiol. 2001;39(1):183-90. doi: 10.1128/JCM.39.1.183190.2001. [PubMed: 11136768].

52. Jones RN, Anderegg TR, Swenson JM, Quality Control Working G. Quality control guidelines for testing gram-negative control strains with polymyxin B and colistin (polymyxin E) by standardized methods. J Clin Microbiol. 2005;43(2):925-7. doi: 10.1128/JCM.43.2.925-927.2005.
[PubMed: 15695708].

53. Nicodemo AC, Araujo MR, Ruiz AS, Gales AC. In vitro susceptibility of Stenotrophomonas maltophilia isolates: comparison of disc diffusion, Etest and agar dilution methods. J Antimicrob Chemother 2004;53(4):604-8. doi: 10.1093/jac/dkh128. [PubMed: 14973153].

54. Tan TY, Ng LS. Comparison of three standardized disc susceptibility testing methods for colistin.J Antimicrob Chemother. 2006;58(4):8647. doi: $10.1093 / j a c / d k l 330$. [PubMed: 16905528]. 